\title{
Max Weber como profesor de teoría económica
}

\author{
Fernando Leal-Carretero \\ Departamento de Estudios Socio-Urbanos. Universidad de Guadalajara \\ ferlec@hotmail.com
}

Recibido: 23-08-2010

Aceptado: 24-01-2011

\section{Resumen}

Estamos acostumbrados a pensar en Max Weber como un jurista convertido en sociólogo histórico que toda su vida estudió cuestiones económicas. Podría sorprender entonces que durante algunos años de su carrera académica, de 1894 a 1898, haya sido nombrado profesor de economía teórica y que en efecto haya programado y dictado cátedra con el contenido nominal de la teoría económica. Es bien sabido que en el Methodenstreit, el cual había estallado una década antes de esta actividad docente, Weber se había declarado a favor de los teóricos y contra los historicistas. La reciente publicación de todos los materiales existentes de sus cátedras nos permite examinar la medida real de su compromiso con la teoría económica. El resultado de ese examen confirma tanto lo que salta a la vista en sus obras publicadas como el juicio de aquellos teóricos de la economía que lo habían conocido personalmente, a saber que Weber nunca entendió de qué trata la teoría económica o cómo usarla.

Palabras clave: teoría económica; disputa de los métodos; sociología clásica; historicismo; metodología.

\section{Abstract. Max Weber as a professor of theoretical economics}

We are used to think of Max Weber as a lawyer-turned-historical-sociologist who dedicated his life to study economic questions. It can come as a surprise that during a few years of his academic career, from 1894 to 1898 , he was nominated professor of theoretical economics and actually planned and delivered ex cathedra series of lectures that were nominally about economic theory. It is well known that in the Methodenstreit, which had erupted a decade earlier than this lecturing activity, Weber came publicly in favor of the theorists and against the historicists. The recent publication of all extant materials related to his lectures allows us to examine the real measure of his commitment to economic theory. The result of such examination confirms what is plain from his published works as well as the judgment of those economic theorists who knew him personally, namely that Weber never understood what the theory of economics is about or how to use it.

Keywords: economic theory; methodenstreit; classical sociology; historicism; methodology. 


\section{Sumario}

1. Las cátedras de Weber a vuelo de pájaro

2. La disputa de los métodos

3. El punto de partida del curso de Weber
4. Los dos errores de Weber precisados

5. Conclusión

Referencias bibliográficas

Pocas personas conocen (y de esas son poquísimas las que toman en serio) el hecho de que Max Weber fue profesor de economía en un periodo de su vida, para ser exactos entre 1894 y 1898. Que haya sido antes profesor de derecho es probablemente más conocido y se dirá que no podía ser de otra manera habida cuenta de su formación profesional como abogado; y que al final de su vida, después de un largo paréntesis en que nuestro autor abandonó completamente la docencia, haya venido a ser profesor de sociología y de historia (social y económica), eso es sin duda lo que mayormente se toma en cuenta. ¿Pero profesor de economía? ¿Cómo es eso? Todos saben ciertamente que Weber se interesó muy a su manera siempre por cuestiones económicas, y muy especialmente por cuestiones de historia económica, sociología económica y política económica ${ }^{1}$. No obstante, que haya enseñado economía, lo que se llama economía, es decir teoría económica, eso sí que para muchos será una novedad y a todos sonará más bien raro.

En las historias de la economía, entendida como una de las ciencias sociales, y por cierto la más potentemente teórica de todas ellas, no se reconoce a Max Weber como uno del gremio. Ni por piensos podemos decir pues de este por demás notable e influyente pensador y estudioso alemán que fue economista; ni él pretendió serlo jamás. Y sin embargo, he aquí (y la cosa es innegable) que dio clases de economía. Dio sin duda también clases de historia de la economía, de política económica, del movimiento obrero, de «ciencia de las finanzas» (que era por entonces una disciplina no teórica sino histórica) y otras más; pero el caso es que dio también clases de «economía general» y «economía teórica», que eran por entonces los nombres que se le daban a la teoría económica. En concreto impartió las cátedras de teoría económica, en seis semestres diferentes, cuatro en la Universidad de Friburgo (1894-B de 4 horas semanales, 1895-B, 1896-A y 1896-B todos de 5 horas por semana) y dos en la Universidad de Heidelberg (1897-A de 6 y 1898-A de 5 horas semanales) ${ }^{2}$.

1. Al lector de habla hispana le serán perfectamente familiares obras como Economía y sociedad, la Historia económica general y las monografías de sociología de la religión (y entre ellas muy especialmente la famosísima sobre La ética del protestantismo y el espiritu del capitalismo). Ninguna de ellas contiene nada que pueda llamarse teoría económica, aunque algunos conceptos de esta teoría aparecen aquí y allá. Se le ha hecho recientemente una especie de santo patrón de la nueva sociología económica (Swedberg, 1998), en la cual también aparecen conceptos de la teoría económica, pero nada más. Por cierto, el lector podría encontrar útil comparar el presente trabajo con Swedberg (1999).

2. Entiendo por «cátedra» (grosse Vorlesung) la serie de conferencias que contiene el material más importante de un área de estudio. Max Weber había sido en efecto llamado a las dos 


\section{Las cátedras de Weber a vuelo de pájaro}

De esas cátedras no sabíamos hasta ahora nada con detalle, excepto por una solitaria publicación en 1990 de dos cuadernillos impresos que Weber preparó para sus estudiantes del último curso que impartió (en Heidelberg durante el ciclo 1898-A), justo por la época en que sufrió ese colapso nervioso que lo postró hasta 1904, año en que reaparecería en la escena académica alemana con su Ética protestante. No sabemos si el colapso nervioso tuvo algo que ver con el tremendo esfuerzo que hizo por intentar cumplir con sus obligaciones como catedrático de teoría económica, pero lo cierto es que no volvió a intentar enseñarla nunca más. Los cuadernillos mencionados, editados en facsímil, contienen, respectivamente, una bibliografía de los libros y artículos relevantes para cada uno de los temas en que Weber pensaba dividir su curso, y una lista de esos temas, ordenados y etiquetados como «libros» y "parágrafos», a la manera de alguien que piensa en una futura publicación (Weber, 1990). Para comodidad del lector y apoyo de la discusión que sigue he tabulado la división del curso así publicada en el Cuadro 1.

Nuestras noticias sobre esa parte de la actividad docente del autor alemán han mejorado notablemente con una publicación reciente: en el marco de las obras completas de Max Weber ha aparecido un nuevo y flamante volumen (Mommsen, 2009), el primero de la serie III que contendrá tanto los manuscritos que se conservan de Weber acerca de sus cursos magistrales como los apuntes de clase que aún tenemos de sus alumnos. Huelga decir que este volumen contiene para empezar una reimpresión de los cuadernillos mencionados (Mommsen, 2009:81-154), pero sobre todo las notas desperdigadas que Weber utilizaba para apoyar la improvisación oral en clase (Mommsen, 2009:157702). Gracias al trabajo verdaderamente hercúleo de descifrar todas esas notas de caligrafía casi ilegible y dispuestas caóticamente en muchas cuartillas podemos ahora tener una idea bastante precisa de Max Weber como catedrático de teoría económica. Por ello podemos estar agradecidos al profesor Wolfgang Mommsen, decano de los estudios weberianos en el mundo, el cual desgraciadamente murió antes de poder concluir esta publicación.

Para empezar, dos observaciones sobre contenido y disposición de este curso de acuerdo con el Cuadro 1. La primera es de forma. Los lexemas que utilizaban (y en parte siguen utilizando) los alemanes para referirse a las cosas económicas presentan mayor variación que en español. El nombre escueto Wirtschaft se refiere principalmente a las actividades económicas humanas en general, independientemente de si ellas ocurren de forma aislada (como en la novela de Robinson Crusoe), dentro de un pequeño grupo o comunidad, entre grupos o comunidades, dentro de un estado (imperio, ciudad, nación) o entre

universidades mencionadas arriba no como profesor asistente o asociado de economía teórica, sino como su profesor titular o catedrático (ordentlicher Professor). Los detalles de sus cátedras se pueden consultar en Mommsen (2009:64 y 8-21 para una versión más pormenorizada sobre cómo fue Weber nombrado catedrático). 
Cuadro 1. La división del curso magistral de teoría económica dictado por Max Weber en el ciclo 1898-A en la Universidad de Friburgo (Fuente: Mommsen 2009:182-188)

$\begin{array}{lc}\text { Introducción } & \begin{array}{l}\$ 1 \text {. Tareas y métodos de la economía teórica [theoretische } \\ \text { Nationalökonomie] }\end{array} \\ \begin{array}{l}\text { Libro I. Los fundamentos } \\ \text { conceptuales de la teoría } \\ \text { de la economía nacional } \\ \text { [Volkswirtschaftslehre] }\end{array} & \begin{array}{l}\$ 3 \text {. La economía [Wirtschaft] y sus fenómenos elementales } \\ \text { nos elementales }\end{array}\end{array}$

Libro II. Los fundamentos naturales de la economía [Wirtschaft]
$\$ 4$. Las condiciones naturales de la economía [Wirtschaft] $\$ 5$. La población

\$6. Los fundamentos biológicos y antropológicos de la sociedad

\$7. Relación de la economía [Wirtschaft] para con los demás fenómenos culturales, especialmente el derecho y el estado

Libro III. Los fundamentos históricos de la economía nacional [Volkswirtschaft]

\$8. Los estadios previos típicos de la economía nacional [Volkswirtschaft]

$\$ 9$. El desarrollo económico [ökonomische Entwicklung] de la antigua cultura costera
$\$ 10$. Los fundamentos agrarios de la cultura medieval del interior

\$11. La economía urbana [Stadtwirtschaft] y el origen de las formas empresariales modernas

$\$ 12$. El surgimiento de la economía nacional [Volkswirtschaft]

Libro IV. Los estadios evolutivos de la teoría económica [Wirtschaftstheorie]

\$13. La ciencia económica [Wirtschaftswissenschaft] hasta la creación de la teoría económica [Wirtschaftstheorie] liberal

\$14. La teoría económica [Wirtschaftstheorie] de la llamada economía nacional clásica [klassische Nationalökonomie]

$\$ 15$. Las bases teóricas del socialismo científico

$\$ 15$ a. Las principales corrientes modernas de la teoría

Libro V. El análisis teórico de la moderna economía comercial

[Verkehrswirtschaft]
$\$ 16$. La producción y sus problemas teóricos

$\$ 17$. El comercio [Verkehr] y sus problemas teóricos

$\$ 18$. Distribución y consumo y sus problemas teóricos

$\$ 19$. Los principios y formas organizacionales regulativas de la satisfacción de necesidades mediante el comercio y las empresas vistas en su función y sus tendencias evolutivas

Libro VI. Desarrollo y aná- \$20. [Sin título]

lisis de los ideales económicos y sociales [ökonomische und soziale Ideale] 
estados. De hecho, Weber la usa con frecuencia justo para lo que él identifica como estadios prenacionales e incluso preestatales de la actividad económica humana; en ese sentido Wirtschaft contrasta con el nombre compuesto Volkswirtschaft, que traduce el sintagma political economy de la tradición inglesa, y cuya mejor traducción es probablemente "economía nacional» ${ }^{3}$. En cambio, cuando el énfasis conceptual recae sobre la actividad comercial se habla de Verkehrswirtschaft y cuando el énfasis es sobre la teoría económica como tal se habla de Wirtschaftstheorie. A pesar de eso, el término paralelo para designar no el tema de estudios de la economía, sino la disciplina misma que estudia la economía en general, es Ökonomie, y más particularmente Nationalökonomie si estudia la economía nacional; de esa manera, para los alemanes en general y para Weber en particular la teoría económica (Wirtschaftstheorie) es solamente una parte de la economía (Ökonomie o Nationalökonomie), a saber su parte general y teórica. De allí el título de la publicación que estamos considerando aquí: «economía nacional general o teórica» (allgemeine oder theoretische Nationalökonomie).

Mi segunda observación es de contenido. Si el lector examina con cuidado en el Cuadro 1 las distintas partes del curso de Max Weber, verá que el espacio dedicado estrictamente a la exposición de la teoría económica es muy pequeño, y se reduce en rigor al «libro» $V$, y dentro de él realmente sólo a los $\$ \$ 16$, 17 y 18 , es decir el $15 \%$ de un curso que debería todo él tratar de teoría económica y de ninguna otra cosa. Considere en efecto el lector que el $\$ 1$ es meramente introductorio y metodológico; que los $\$ \$ 2-3$ se ocupan de definiciones de conceptos (los cuales son, si se quiere, la antesala de la teoría, pero no todavía ella misma); que los $\$ \$ 4-12$ pertenecen a la historia económica (incluida la prehistoria); que los $\$ \$ 13-15$ (así como el $\$ 15 \mathrm{a}$ ) tratan de la historia del pensamiento económico; que en el $\$ 19$ se vuelve a la perspectiva de la historia económica; y finalmente que en el $\$ 20$ la discusión es más bien política ${ }^{4}$.

3. Ojo: no «economía política», que es una expresión que hoy día cada quien la entiende de manera distinta y a menudo muy lejana de su acepción original. En efecto, nunca está de más recordar que el substantivo «economía», de origen griego, en su uso ordinario abarca solamente las actividades económicas de una unidad doméstica (hacienda, villa, rancho, granja). Ya Aristóteles — o quien haya escrito el texto atribuido a Aristóteles— había por ello sentido la necesidad de añadir un adjetivo cuando se trataba de algo más que de economía

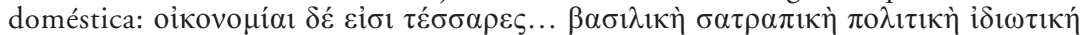
(Oeconomica B 1345b11-14): «hay cuatro economías... basílica, satrápica, política, idiótica (es decir, del rey o emperador, de los gobernadores de las provincias imperiales, de la ciudad estado, de los individuos)». No de otra manera se procedió en la Europa moderna al usar el substantivo "economía» con un modificador (political economy, économie politique, économie sociale, economia civile, Volkswirtschaft, Nationalökonomie) para indicar que el tema de estudio son las mismas actividades propias de una economía doméstica, pero en la forma y magnitud en que ocurren dentro de una nación europea moderna.

4. El editor del curso de Weber confirma esta apreciación: «[L]as partes más extensas [del curso] se ocupan de reconstruir históricamente la formas de economía y las condiciones de vida que condicionan tales formas» (Mommsen 2009:31). Yo añadiría: no hay nada de teoría: todo es historia precedida (o acompañada) de definiciones de conceptos. 


\section{La disputa de los métodos}

Este espacio tan pequeño (insisto: el 15\%) que parece asignarse a la exposición de la teoría incluso dentro de un curso explícitamente dedicado a enseñar la teoría es característico de la manera en que se enseñaba economía en la Alemania decimonónica, y no debe en rigor causar sorpresa. Contra esta manera de proceder de los profesores de economía alemanes se alzó la voz de Carl Menger, el economista austriaco que descubrió - junto con William Stanley Jevons y Léon Walras e independientemente de ellos - la manera de reconstruir la teoría económica clásica sobre la base del principio marginalista (Menger, 1871). Años más tarde el mismo Menger escribió un libro dirigido contra el historicismo ateórico de los alemanes (Menger, 1883) en el que echó a andar lo que se conoce como la "disputa de métodos» (Methodenstreit; para una excelente discusión de ella véase Schumpeter 1954:807-820).

La disputa de los métodos, la primera y más famosa en la historia de las ciencias sociales, gira en torno a la pregunta por el origen, naturaleza y función de la teoría en economía (aunque el planteamiento se puede generalizar en principio a cualquier ciencia social). Gustav von Schmoller, el líder de los historicistas, respondió con una reseña crítica de Menger (1883), la cual se publicó en la revista que él dirigía (Schmoller, 1883), a saber el Anuario de Legislación, Administración y Economía del Imperio Alemán - mejor y más elocuentemente conocida y citada como Schmollers Jahrbuch o el Anuario de Schmoller-, la cual era por entonces la más importante revista de economía en el mundo de habla alemana. Menger por su parte elaboró una réplica a la reseña de Schmoller redactada como una serie de cartas más o menos ficticias, la cual envió para su publicación en el Schmollers Jahrbuch. Como era de esperarse, el omnipotente editor de la revista no sólo rehusó publicarla sin mayor trámite sino que, cuando se publicó como libro (Menger, 1884) y fue enviada para reseña, Schmoller tuvo la descortesía de enviarla de regreso a su autor sin más trámite (Hayek, 1968:XXII). Con ello la disputa entre los dos profesores se detuvo, y pasó a manos de discípulos, colegas y cofrades, quienes la continuaron por algún tiempo. Hoy día se considera la disputa zanjada a favor de Menger; y aunque la teoría económica ortodoxa de nuestros días (la llamada "economía neoclásica», que desciende directamente de Jevons, Menger y Walras) está, como toda buena teoría científica, envuelta en debates sobre su alcance y límites, la posición particular de Schmoller en la disputa no tiene hoy día ningún partidario 5 .

5. Esto no significa en absoluto que Schmoller no haya tenido enormes méritos como investigador. Para una interesante discusión del proyecto de economía de este autor puede verse Priddat (1995). Tampoco significa que la apuesta institucionalista (presente tanto en las dos escuelas históricas alemanas de economía como en una serie de autores contemporáneos a ellas en el mundo anglosajón) haya desaparecido del mapa. Antes bien, una de las perspectivas más vigorosas en el panorama de la economía contemporánea consiste precisamente en nuevas formas de institucionalismo. Lo importante para los propósitos de este trabajo es que el nuevo institucionalismo utiliza la teoría económica básica (esa de la que Max Weber 
Menger argüía que la teoría económica, como toda teoría científica, constituye una simplificación de los hechos reales, los cuales no es humanamente posible capturar en toda su gigantesca complejidad y por ello justamente se necesita de aquella simplificación. Sólo con ayuda de la teoría podemos orientarnos en los datos y comenzar a comprender, en una primera aproximación, lo que ha ocurrido, ocurre y ocurrirá en el mundo de las actividades económicas humanas. Schmoller argüía en su reseña que eso era verdad de la teoría económica clásica, con cuya ayuda por algún tiempo pudimos atrapar grandes trozos de la realidad, pero que ella se había ya agotado y ahora debíamos proceder de manera puramente empírica, reuniendo enormes bases de datos de la actividad económica humana, con la esperanza de construir algún día una teoría nueva por inducción (en el mejor estilo baconiano). Los historicistas estaban pues empeñados en crear esas bases de datos para un futuro teórico que les sacara jugo. $Y$ vaya que las crearon; pero nunca consiguieron extraer de ellas nada que se pareciese a una teoría económica alternativa.

$\mathrm{Al} \mathrm{lector} \mathrm{probablemente} \mathrm{le} \mathrm{resulten} \mathrm{familiares} \mathrm{los} \mathrm{términos} \mathrm{de} \mathrm{esta} \mathrm{disputa,}$ antigua pero a lo que parece condenada a repetirse. En todo caso no es este el lugar para tomar posición frente a ella. Lo único que me interesa aquí aclarar es cuál era la posición de Max Weber en el debate, tal como ella se desprende no de sus declaraciones abstractas, sino de los cursos efectivamente impartidos por él. En efecto, el autor alemán declaró en público y en privado que consideraba haber Menger tenido razón sobre Schmoller en todos los puntos importantes que se disputaban (Mommsen, 2009:28-29). Lo interesante, sin embargo, no son sus declaraciones de principios, sino su actividad docente real, lo que Max Weber como catedrático de teoría económica verdaderamente enseñó. Hic Rhodus hic salta, como solía repetir el viejo Marx.

Entre los grandes teóricos de la economía que eran contemporáneos de Weber y que él tuvo la ocasión de conocer en su época vienesa, Weber entabló amistad cercana con dos de los más notables, Ludwig Mises y Joseph Schumpeter. Ambos apreciaron y admiraron mucho en Weber al gran estudioso y erudito en materia histórica y sociológica, pero ambos también expresaron el mismo juicio: que Weber jamás llegó a conocer la teoría económica de verdad (Mises, 1929; Schumpeter, 1954). Es difícil imaginar que en este punto se hayan equivocado estos dos expertos. Un examen atento de todos los documentos de que disponemos ahora muestra que ese doble juicio sobre los conocimientos y capacidades teóricas de Weber es correcto; y me parece que podemos decir con bastante precisión en qué consisten las limitaciones de Weber.

no quiso saber), si bien modificando sus condiciones de aplicación y en algunos casos introduciendo elementos tomados de la historia, de otras ciencias sociales así como de las ciencias cognitivas y biológicas. Basta citar los nombres de George Akerlof, Vernon L. Smith, Richard Thaler, Herbert Gintis, Paul Krugman, Elinor Ostrom, Bruce Bueno de Mesquita, Avner Greif o Ken Binmore para hacerse una idea de la riqueza y variedad del institucionalismo teórico moderno, muy diferente del institucionalismo ateórico de Weber. 


\section{El punto de partida del curso de Weber}

Debemos empezar con el punto de partida de Weber, en el que se separa con toda claridad de la teoría económica. La mejor manera es citar los primeros párrafos del segundo cuadernillo que él mismo mandó imprimir para sus estudiantes (Weber, 1990:29; Mommsen, 2009:122). El primer párrafo, bajo el encabezado "Concepto de economía», reza así:

Unter „Wirtschaften” verstehen wir eine spezifische Art äußeren Zweckstrebens - d.h. bewußten planvollen Verhaltens zur Natur und den Menschen -, welches veranlaßt ist durch diejenigen Bedurfnisse, welche äußerer Mittel zu ihrer Befriedigung benötigen - gleichviel ob sie selbst „materieller“ oder „ideeller“ Natur sind, - und welches dem Zweck der Vorsorge fur die Zukunft dient.

Por «economizar» entendemos un modo específico de perseguir un fin exter$n o$, es decir de conducta consciente y planificada frente a la naturaleza y los seres humanos, la cual es ocasionada por aquellas necesidades, que requieren medios externos para su satisfacción - no importa si son de naturaleza «material» o «ideal» -, y la cual sirve al fin de procuración para el futuro.

El lector avezado de Weber reconocerá la manera típica en la que este autor procede para construir sus definiciones conceptuales. No otra cosa encontramos en Economía y sociedad («Doctrina de las categorías sociológicas», cap. II, $\$ 1$ ), excepto que en este último libro hay más calificaciones y anotaciones. Pues bien sobre la base de esta definición de «economizar» Weber define «economía» en el segundo párrafo como sigue:

„Wirtschaft" ist der Complex der Maßnahmen, welche durch das Wirtschaften eines Individuums oder einer menschlichen Gemeinschaft veranlaßt sind.

«Economía» es el complejo de medidas ocasionadas por el economizar de un individuo o una comunidad humana.

Hasta aquí una vez más nada que no conozcamos ya. En cambio el tercer párrafo, bajo el encabezado «Presupuestos de la teoría abstracta de la economía», contiene algo completamente nuevo e inesperado para alguien acostumbrado a pensar en los términos propios de la teoría económica:

Das Wirtschaften ist dem Menschen durch einen jahrtausendelangen Anpassungsprozeß anerzogen. Das Maß des planvollen Wirtschaftens im modernen Sinn war und ist historisch, nach Rasse und - auch innerhalb der modernen occidentalen Cultur - nach Beruf, Erziehung, Intellekt und Charakter der Individuen sehr verschieden, durchweg aber unvollkommen entwickelt; demgemäß ist auch der Spielraum, den rein wirtschaftliche Motive im Kreise der das Handeln des Einzelnen bestimmenden Triebfedern einnehmen, ein historisch und individuell höchst wandelbarer. Die abstrakte Theorie geht von dem modernen occidentalen Typus des Menschen und seines Wirtschaftens aus. Sie sucht zunächst die elementarsten Lebensphänomene des wirtschaftlich voll erzogenen Menschen zu ermitteln. 
El ser humano ha sido educado para economizar a través de un proceso de adaptación que ha tomado miles de años. La medida en que haya un economizar planificado en el sentido moderno era y es algo histórico, muy diferente según la raza y — también al interior de la cultura occidental moderna - según la profesión, la educación, el intelecto y el carácter de los individuos, pero en todos ellos algo imperfectamente desarrollado. De acuerdo con esto también el margen de movimiento que tienen los motivos puramente económicos en el círculo de las motivaciones que determinan la acción del individuo es algo histórico y que presenta una altísima variabilidad individual. La teoría abstracta arranca del tipo occidental de ser humano y de economización. Busca ella de entrada identificar los fenómenos vitales más elementales del ser humano que ha sido plenamente educado.

Vemos en este pasaje crucial que Weber sigue siendo claramente historicista. Si la teoría económica (o para usar su expresión, la teoría "abstracta», como si hubiera teorías que no lo fueran) parte de un tipo ideal de ser humano que ha sido tomado de una época histórica particular, eso significa que los principios, modelos y modos de argumentar que constituyen aquella teoría valen en principio solamente de los seres humanos que se acerquen a ese tipo ideal, y tienen poca o ninguna validez para seres humanos de otras épocas. De hecho, podemos decir que Weber es igualmente culturalista, ya que insiste en que el economizar es algo que se enseña, en lo que se entrena, adiestra y socializa. Esto llenará de alegría los corazones de algunos lectores; pero es directamente opuesto al espíritu de la teoría económica.

Detrás de las definiciones de Max Weber hay varios malentendidos. En primer lugar, es cierto que la teoría económica trabaja con un modelo de ser humano que es una simplificación del ser humano real; y no podría ser de otra manera por la sencilla razón de que toda teoría trabaja con modelos que son simplificaciones de la realidad. Sin simplificaciones no hay teoría; y una teoría en cierto modo no es sino una gigantesca simplificación, o mejor una serie de simplificaciones conectadas lógicamente entre ellas. Al modelo simplificado de ser humano con el que trabaja la teoría económica se lo llamó en inglés al menos desde la segunda mitad del siglo XIX economic man, una expresión que ha pasado a otras lenguas (y finalmente al inglés mismo) bajo la forma latina homo oeconomicus. Sin embargo, el homo oeconomicus no es un tipo ideal, es decir no es una versión estilizada, exagerada y caricaturizada de un modo de ser histórico (que esto y no otra cosa es, al decir de Weber, un tipo ideal), sino que fue construido para representar un componente de cualquier ser humano en posesión de sus facultades ${ }^{6}$.

6. Nadie parece saber a ciencia cierta el origen de la expresión inglesa economic man ni de la versión latina homo oeconomicus. Los primeros pasajes que se citan en la literatura son para la expresión inglesa Ingram (1888:108; cf. Persky, 1994:222) y para la latina Pantaleoni (1889, passim; cf. O’Boyle, 2007:322). En todo caso, por el tono que estos autores usan, es obvio que no pretenden introducir un neologismo, sino sólo retomar una expresión en boga. 
Miremos las cosas despacio. ¿Cuál sería ese componente tan notable que la teoría económica destaca para formar el modelo de ser humano que llamamos homo oeconomicus? Weber nos dice que el punto crucial es la operación llamada «economizar», es decir ahorrar para el futuro. ¿Por qué es importante economizar? Pues porque no vivir al día ni consumir todo lo que se tiene en el presente, sino ahorrar una parte para el futuro es importante para la satisfacción de las necesidades humanas, por cuanto estas no se agotan en el presente sino que se extienden al futuro. En eso de ver el economizar como la característica del homo oeconomicus Weber es fiel seguidor de todos los economistas alemanes de la escuela histórica, quienes siempre parten de este aspecto de previsión y procuración a la hora de construir sus tratados de economía (a diferencia de los puntos de partida de los autores ingleses y franceses). Y sin duda es correcto que los seres humanos necesitamos aprender a ahorrar (véase cómo los niños tienden a vivir sólo en el presente) e incluso que hay muchos que nunca lo aprenden (de allí la frase weberiana de que el economizar planificado "presenta una altísima variabilidad individual»). Por otro lado, cuesta mucho trabajo imaginar grupos de seres humanos en los que no existan formas de ahorro y previsión para el futuro. Todo ser humano en plena posesión de sus facultades economiza, y lo hace en múltiples áreas y niveles de su vida (piénsese por ejemplo en el corredor que administra con cuidado sus energías). Lo que Weber nos está queriendo decir es pues que la humanidad occidental ha creado diversos dispositivos culturales - desde la doble contabilidad hasta la ética protestante - para hacer de la economización algo tremendamente desarrollado y efectivo. Y podrán los historiadores disputar sobre las cuestiones de detalle (por ejemplo, las tesis de Weber sobre el protestantismo y el capitalismo han sido y seguirán siendo objeto de debates), pero nadie puede negar que muchas cosas han cambiado en los procedimientos de economización utilizados. Pero de allí no se sigue que «el ser humano que economiza» es un tipo ideal extraído de consideraciones históricas específicas, sino cuando mucho que tal sería el «ser humano que economiza mediante los métodos occidentales modernos». Ver esto es darse cuenta de la tautología implícita en los párrafos citados.

En segundo lugar, el homo oeconomicus que tanto aborrecían los historicistas no era tanto el ser humano que economiza —en general o con los métodos occidentales modernos - sino el ser humano en cuanto está motivado exclusivamente por sus propios intereses. Esto dio pie a que los historicistas y otros humanitarios protestaran contra el egoísmo e individualismo que veían entronizarse como principio de la ciencia. Y no les faltaba razón habida cuenta de algunos excesos expositivos producto del celo y el entusiasmo de los primeros descubridores de los efectos positivos no buscados que resultan al agregarse las acciones individuales. Sin embargo, esos bien-pensants no veían entonces, como no ven ahora, el fondo de las cosas: que el grado de egoísmo e individualismo depende de la naturaleza de los intereses que una persona tiene: para la teoría económica, la Madre Teresa de Calcuta está tan motivada por sus propios intereses como Al Capone; simplemente los intereses de la primera son muy dife- 
rentes de los del segundo ${ }^{7}$. Se podría entonces argumentar igualmente que nadie puede decir a priori si egoísmo e individualismo son un producto de la cultura y la época histórica; pero no me detengo más en esto porque en todo caso no es este homo oeconomicus del que Weber nos habla en sus definiciones.

En tercero y último lugar el verdadero modelo de ser humano con el que trabaja la economía no es ni el tradicional que repite Weber (el homo que economiza) ni el que causó y sigue causando tanto escándalo (el homo que sigue sus propios intereses), sino el que tiene que tomar decisiones sobre lo que va a hacer, y para ello compara las acciones alternativas que podría elegir en su lugar. Esta comparación (hoy conocida como el cálculo de costos y beneficios) es el corazón del asunto, y no el economizar. Este es en efecto siempre y necesariamente un término relativo: al economizar yo en algo dejo de economizar en otra cosa; y a veces economizar en algo no es el medio más eficaz de satisfacer mis intereses, e incluso puede ir en contra de mis intereses. Nada de eso está presente ni en las definiciones que Weber pone al principio de su curso ni en ninguna otra parte del mismo. Y huelga decir que el tomar decisiones y sopesar alternativas no puede considerarse un tipo ideal (es decir, tomado de un momento histórico); lo más que podemos decir es que esa propiedad general de las acciones humanas se ha perfeccionado mediante los métodos occidentales, con lo que volvemos a la tautología.

Resumiendo: si Weber piensa que economizar a la manera occidental moderna es un tipo ideal tomado de ese momento histórico que es el occidente moderno, dice una tautología; si piensa que economizar en general es un tipo ideal tomado de un momento histórico (el que fuera), dice algo falso, ya que el economizar es parte del ser humano; pero si piensa que economizar en general, independientemente de que sea o no un tipo ideal tomado de un momento histórico, es de lo que trata la economía, dice algo aun más falso, porque de lo que trata la economía es de las acciones y sus costos; y si piensa que la economía trabaja con tipos ideales, del economizar o de cualquier otra cosa, entonces dice lo más falso de todo, porque la economía no es en absoluto una ciencia histórica, aunque se pueda aplicar, como teoría, a la historia ${ }^{8}$.

7. Sobre esto ya habló con toda claridad Wicksteed (1910:163-184). Con todo merece la pena recordar que nuestros humanitarios echan la culpa al «capitalismo» de todos los males imaginables, incluidos el egoísmo, el individualismo y esta especie aparentemente nueva que es el «consumismo». Cualquiera pensaría que antes del advenimiento de esa cosa obscura que es el «capitalismo» los seres humanos eran buenos, nobles, honestos, siempre dispuestos a ayudar y en fin que poseían todas las virtudes imaginables que el «capitalismo» les arrebató. De hecho, el «capitalismo» no es uno sino múltiple (sobre eso véase la lúcida e informada monografía de Albert 1991). En todo caso, la discusión sobre los méritos y deméritos morales del capitalismo no es una cuestión relevante para los propósitos de este trabajo, por cuanto semejantes simplezas no aparecen en Weber.

8. Este punto fue discutido con enjundia y maestría ya por Mises (1929), aunque desgraciadamente Weber había muerto para entonces y no tuvo ocasión de replicar (véase también Mises 1957:183-197 y 303-320). Hoy día ha aparecido un nuevo defensor de la idea de que la economía es una ciencia histórica (Rosenberg, 2009); pero la delicada tesis de este autor no tiene nada que ver con la idea (en último término absurda) de que cada periodo histórico requeriría una teoría diferente (véase más adelante nota 14). 
Con este punto de partida tan erróneo, y tan característico de Max Weber, no debe sorprender que el resto de sus disquisiciones supuestamente teóricas no lo sean. Lo que encontramos en el curso magistral del autor alemán es, por un lado, una serie de distinciones, clasificaciones y definiciones; y por el otro una serie de aperçus sobre el desarrollo histórico de las instituciones (particularmente las europeas) y de las ideas (particularmente las de economistas e historiadores económicos). Magníficos todos si se quiere, y hasta utilísimos; pero lo que no encontramos es una exposición de la teoría económica. Y gracias a la publicación de su cátedra de economía podemos ver que los problemas de Weber con la teoría son exactamente dos. Uno de ellos es confundir la teoría con un conjunto de conceptos; el otro es confundir la teoría con la descripción; y si cualquiera de ellos es un error fatal, juntos c'est la catastrophe. Voy a abundar sobre ambos errores porque en mi experiencia son muy comunes en investigaciones científico-sociales.

\section{Los dos errores de Weber precisados}

El primer error de Weber consiste en que las operaciones lógicas de distinguir, clasificar y definir con extremo cuidado y meticulosidad los conceptos económicos (por ejemplo, bien, bien económico, intercambio, precio, comercio, etc.) son confundidas con la muy diferente operación lógica de formular una teoría, es decir un cuerpo de proposiciones encadenadas lógicamente y con cuya ayuda podemos plantear preguntas, formular hipótesis, construir modelos, diseñar métodos para hacer observaciones, recoger datos y analizarlos, en fin para razonar, argumentar y concluir sobre los fenómenos económicos. Las distinciones, clasificaciones y definiciones tienen en economía el mismo valor que tienen en cualquier ciencia, a saber el de prestarse para analizar situaciones económicas y argumentar sobre ellas. El valor de las categorías, de los Grundbegriffe y sus definiciones, es puramente relativo: están al servicio de la teoría y en la medida en que no se utilicen para argumentar económicamente no sirven de nada. Alguien puede repetir la definición más bella y exacta de un concepto tan importante como el de costo de oportunidad sin que por ello pueda usarlo para entender lo que está ocurriendo frente a sus narices?.

9. Kant dice en su Crítica de la razón pura (A133, B172, nota) que hablamos de «entender» algo en dos sentidos completamente diferentes. Si alguien entiende un concepto o principio en toda su generalidad, no significa que lo entienda en el sentido de poder aplicarlo a un caso particular. Así, un físico puede entender perfectamente cómo funciona un automóvil y ser incapaz de aplicar lo que sabe a detectar un problema que tiene este coche (o incluso el tipo de problemas más comunes en todos los coches o en ciertos tipos de coche). $\mathrm{Al}$ revés, un mecánico puede entender de coches en el segundo sentido y al mismo tiempo no entender en absoluto los conceptos y principios de un motor de combustión interna. Cuando examinamos la exposición de Weber, se vuelve claro que (sin tomar en cuenta por ahora muchas cosas que omite) entiende de teoría económica en el primer sentido, pero no en el segundo, mientras que un economista se distingue como tal en que domina ambos aspectos de la teoría, pero sobre todo el segundo. 
Para muestra basta un botón. En las notas para su curso Weber discute sobre si algo es o no es un bien económico y en particular sobre si las «relaciones sociales» lo son. Esta cuestión de si las relaciones sociales son o no son bienes económicos fue tan traída y llevada en el siglo XIX como hoy día se lleva y trae el "capital social» (o el "cultural», el «simbólico», y no sé cuántos más "capitales»). En rigor se trata de la misma pregunta y de la misma inconclusión por cuanto se confunden los conceptos, las distinciones conceptuales y las definiciones con la argumentación propia de la teoría ${ }^{10}$. Nibil nouum sub sole. Pero eso mismo muestra que hablar de Weber no tiene un interés puramente histórico, por cuanto se trata de las mismas taras metodológicas que siguen afligiendo a la investigación en ciencias sociales más de un siglo después. Me explico.

Tanto en el resumen que imprimió para sus alumnos como en los apuntes que Mommsen ha editado con tanto cuidado, Weber nos ofrece una discusión sobre lo que debe o no debe contener el concepto de «bien económico». Su punto de partida era la idea que había tres clases de bienes económicos ${ }^{11}$. La primera clase era la de los bienes materiales; la segunda la de los servicios prestados a otros; la tercera la de las relaciones. La primera clase era aceptada por todos; si los bienes materiales no son bienes económicos, sería difícil decir qué otra cosa podría serlo. La segunda clase era un tanto controvertida, pero a final de cuentas se aceptaba porque era claro que los servicios satisfacen necesidades tanto como lo hacen los bienes materiales. La tercera clase, que era la más obscura, era también la más controvertida. Bajo la etiqueta de "relaciones» se escondían todo tipo de cosas: desde la clientela que tiene un comerciante o profesionista hasta sus privilegios, concesiones y monopolios, y desde las relaciones familiares y de amistad hasta las creadas y sostenidas por la existencia y funcionamiento del aparato estatal. ¿Son o no son bienes económicos? Weber debate la cuestión, pero lo que le preocupa es establecer una terminología consistente, y aunque admite tener algunas dudas, concluye que las relaciones no pueden ser bienes económicos, porque considerarlos tales sería algo puramente formal (Mommsen, 2009:219). Weber no explica muy bien qué es esto de «formal», aunque no parece imposible que se refiera a la discusión de lo que parece ser la misma cuestión en la primera obra publicada por Böhm-Bawerk (1881), el notable discípulo de Menger.

Sin embargo, la diferencia entre los propósitos de Weber y los de BöhmBawerk es flagrante y decisiva. Böhm-Bawerk, al igual que su maestro Menger,

10. En lo tocante al «capital social» ya ilustres economistas como Kenneth Arrow, Robert Solow y Partha Dasgupta han expresado que se trata solamente de una metáfora y por cierto poco acertada. Ojo: los tres autores tienen enorme simpatía por las intenciones de quienes hablan de "capital social»; simplemente desde el punto de vista de la teoría económica no se trata de capital y hablar como si lo fuera no ayuda en nada (véanse las contribuciones de los tres autores en Dasgupta y Serageldin 2000). El punto no es conceptual; y el error no se resuelve buscando una definición más precisa, por ejemplo a la manera de Weber.

11. Esta idea está muy arraigada en la enseñanza de la economía en Alemania y se repite en todos los manuales a lo largo del siglo XIX. Así aparece desde el principio del libro que se considera fundacional de la escuela histórica alemana (Roscher, 1843:3). 
es puntillosísimo en el intento de precisar los conceptos, y hasta allí parece perseguir el mismo objetivo que Weber; pero se trata de una apariencia falsa. Ambos autores concluyen que las relaciones no deben ser considerados bienes económicos, pero cuando leemos con cuidado la discusión de Böhm-Bawerk, vemos que su propósito es evitar errores en la teoría económica, especialmente en las ramas de ella dedicadas al estudio del crédito y del capital (1881:147153). No puedo detenerme a explicar esto en detalle, pero lo que preocupa a Böhm-Bawerk, como en general ha preocupado siempre a los economistas de la llamada escuela austriaca, son los errores teóricos que subyacen a los excesos financieros que a su vez conducen a crear burbujas como la que en este momento padecemos (véanse por ejemplo Mises 1912, Rothbard 1983, Huerta de Soto 2009) ${ }^{12}$. Nada de esto encontramos en Weber, quien no tiene nada importante que decir sobre el crédito o el capital ni en este pasaje de su curso ni en ningún otro. (Y eso no es casualidad, ya que en Economía y sociedad podemos constatar la misma ausencia.) La puntillosidad definicional de Weber se parece a una bicicleta volcada a cuyas ruedas se ha imprimido una gran velocidad, pero sin que la bicicleta vaya a ninguna parte ${ }^{13}$.

Hasta aquí el primer error de Weber respecto de la teoría económica. Su segundo error reside en imaginar que la descripción de instituciones es algo separado de, y por ello puede substituir a, la teoría. Es difícil juzgar cuál era exactamente el contenido de la exposición oral de Weber a partir de las notas escritas que dejó. Su esposa Marianne reporta «su gusto por la estructura transparente y rigurosamente articulada» de sus cátedras de economía teórica y práctica, y describe cómo el profesor Weber improvisaba a partir de notas con-

12. Estas referencias no deben entenderse como si el autor de este trabajo creyese que las apuestas teóricas de los llamados economistas austriacos fuesen las únicas válidas o dignas de tenerse en cuenta. Cito a estos autores solamente porque el punto histórico que me interesa aquí es si una cuestión conceptual (como la que me sirve aquí de ejemplo, a saber si las relaciones son un bien económico) está animada o no por preocupaciones teóricas: este es el caso de Böhm-Bawerk y los otros autores citados que pertenecen a su progenie con respecto al ejemplo elegido, y justamente no es el caso de Max Weber.

13. La acumulación de definiciones y distinciones de Weber recuerda la descripción que Homans (1964) diera de las «teorías» de Parsons: "proporciona el diccionario de un lenguaje que carece de enunciados» (y aun habría que añadir: «y de argumentaciones»). El hecho no debe sorprendernos, puesto que fue Weber quien indujo a Parsons a abandonar la economía por la sociología, y con ello los enunciados por los conceptos y la teoría por las definiciones (cf. Homans, 1983:24). Nunca está de más decirlo: en el terreno científico (desde las matemáticas puras hasta las ciencias empíricas) las definiciones no tienen sino una función, a saber contribuir a las demostraciones. Sin demostraciones no hay ciencia, y una definición suelta, que no contribuye a una demostración, no sirve de nada. Cuando Einstein insistió en una definición más precisa de simultaneidad, no quería satisfacer pruritos terminológicos sino modificar la teoría física; y cuando los lingüistas debaten sobre la manera correcta de definir un concepto importante, como el de clase de palabras o categoría sintáctica, lo que tienen en la mira es exclusivamente la teoría lingüística como tal. La consecuencia del mal hábito de enredarse con distinciones y definiciones sin ningun proposito teórico es que los estudiantes de ciencias sociales emplean en ellas un tiempo muy valioso que fuera mejor empleado en aclararse qué es lo que están tratando de probar. 
fiando en la inspiración del momento, de manera que «el riguroso aparato conceptual quedara envuelto con la riqueza del saber histórico» $\mathrm{y}$ «la poco usual precisión en el pensamiento se completase por su igualmente poco usual fuerza plástica», concluyendo que el profesor Weber era capaz de hacer comprensible lo más abstracto mediante una serie de ejemplos detallados (Marianne Weber, 1926:241; cf. Mommsen, 2009:32).

No tengo duda alguna de que Max Weber pudiese, a partir de las notas ahora publicadas, completar sus descripciones con ejemplos y más ejemplos tomados de la historia económica que tan bien conocía; de lo que no estoy seguro es de que con ello se hiciese "comprensible lo más abstracto». Todo depende de qué es lo que los estudiantes entiendan por comprensible. Así por ejemplo, uno de esos estudiantes que escuchó la cátedra de Weber sobre teoría económica dice en sus memorias que «le aportaron poco» y que el profesor era "un puro historiador y, como siempre, totalmente asistemático» (Liefmann en Meiner, 1924:157; cf. Mommsen. 2009:32). Ese estudiante era el futuro economista que luego le escribiría a Weber preguntándole por qué no aportaba nada a la teoría económica, a lo que Weber le replicó que no podía estar en todo (correspondencia citada por Hennis, 1987:125-126, n. 25).

En efecto, ni él ni nadie puede estar en todo, y no hay por qué pedirle teoría económica a un autor que como Weber aportó tantas otras cosas. Pero con eso el problema de Weber como profesor de economía no hace sino agudizarse. ¿Qué es lo que él enseñaba entonces en una cátedra oficialmente dedicada a exponer la teoría económica? Tomemos el caso de la bolsa, un tema sobre el que Weber había escrito poco antes de asumir su cátedra de economía general una monografía para la Biblioteca de los Trabajadores que coordinaba Fredrich Naumann (Weber, 1894). Esta obra, no hace mucho traducida al español, revela a su lector lo mismo que hemos dicho antes: muchos detalles históricos sobre las diversas bolsas y nada de teoría económica.

Lo mismo encontramos en las notas de su cátedra. Por ejemplo, en la breve sección en la que habría expuesto un fenómeno tan importante teóricamente como el surgimiento de las dichas bolsas tenemos una serie de frases que interpretadas generosamente darían aproximadamente esto:

El intercambio de mercancías ha pasado de ser un fenómeno recurrente, pero esporádico, a ser un fenómeno que ocurre de manera regular. Las relaciones comerciales se han vuelto fijas y constantes. Con ello se ha producido una transformación de los mercados y ferias de antaño. Antes lo que había era comercio de mercancías presentes con comerciantes itinerantes que tenían que estar igualmente presentes en el momento del intercambio. De esa manera, los mercados internacionales eran pasajeros y transitorios. Hoy día lo que tenemos son empresas comerciales de largo alcance con sucursales en todos los lugares de intercambio. Se han formado comisiones comerciales con encargados que se especializan en un comercio internacional regular y permanente. Se compra y vende todo el tiempo y en muchos lugares; y las mercancías que se intercambian no tienen que estar presentes en el momento de la transacción. En este contexto aparecen las bolsas. (Mommsen, 2009:511.) 
Cualquiera se puede percatar que esto no es sino una dicotomía entre dos tipos de situación comercial, uno antiguo y otro moderno, acompañada de descripciones bastante pedestres y sin ningún asomo de explicación acerca de las acciones humanas que subyacen a las distintas formas de intercambio. La idea de que las descripciones detalladísimas que seguramente añadió Weber de viva voz constituyan una teoría del surgimiento y funcionamiento de las bolsas de valores es sencillamente absurda. Y donde no hay teoría, ninguna descripción puede suplantarla ${ }^{14}$. Algún lector atento al Cuadro 1 podría pensar que la cita que acabo de dar está tomada del libro III, que es claramente historiográfico, mientras que tal vez en el libro $\mathrm{V}$, que es el único que se presenta como teórico (lo dijimos arriba), sí que se dará la teoría de la bolsa. Lamento decepcionarlo, pero tampoco encontramos allí una sola proposición o argumentación teórica.

\section{Conclusión}

Hasta aquí el segundo error. Con ello quedan confirmadas las opiniones mencionadas arriba de Schumpeter y Mises en el sentido de que Weber, por lo demás un estudioso admirable, nunca entendió la teoría económica. Resulta curioso que el editor del curso de Weber diga, a pesar de todo esto, que en vista de lo que sabemos no solamente de los cuadernillos que Weber imprimió para sus estudiantes, «sino todavía más de los manuscritos de notas que aquí se publican por vez primera» el juicio de aquellos economistas debe revisarse (Mommsen, 2009:30). Tal revisión había sido urgida antes por Norkus (2001) sobre la base algo más frágil de los solos cuadernillos.

La idea de revisar los juicios que se han hecho sobre un autor importante es en principio correcta, y por ello es que la he tratado de realizar aquí; pero la implicación de que aquel juicio podría ser erróneo en vista de que «los manuscritos muestran que Max Weber se ocupó muy intensivamente de los problemas de la economía nacional teórica» (Mommsen, 2009:30), es una verdadera suggestio falsi. Nadie niega que Weber se haya ocupado muy intensivamente; pero si lo hizo, la pregunta es si tuvo éxito. Y la respuesta es clara: nunca llegó

14. Vuelva a considerar el lector la cita de Weber con la que comenzamos la discusión, aquella según la cual el homo oeconomicus es un tipo ideal desgajable de un momento histórico y no un modelo teórico aplicable a todos los tiempos y lugares. Si tomamos en serio eso, habría que concluir que cada momento histórico que podamos distinguir requeriría su propia teoría. No habría una teoría general. Es como si alguien dijera que cada lengua necesita de una teoría especial que la explique o que la física no se aplica por igual a todos los lugares y momentos del universo. No digo que eso sea completamente absurdo; pero despierta la sospecha de que lo que no se quiere es tomarse el trabajo de aprender la teoría. En todo caso, incluso los economistas más convencidos de que las particularidades sociales y culturales tienen un efecto sobre el comportamiento económico no están dispuestos a renunciar a la teoría general (véase por ejemplo Gintis, 2009). Una cosa es que la teoría deba aplicarse con cuidado, considerando las variadas circunstancias en que se dan los fenómenos concretos, y otra muy diferente el que cada nueva circunstancia exija su propia teoría. Sobre esto habló ya con gran claridad Pareto (1896), uno de los economistas más dispuestos a combinar la teoría abstracta con los datos empíricos. 
a entender en qué consistía la teoría y nunca se dio el tiempo de averiguarlo ${ }^{15}$. No se puede estar en todo, como él mismo lo dijo.

Con ello concluyo que los méritos de la edición de la cátedra de Weber sobre economía teórica son exclusivamente los propios e importantísimos de la crítica textual, es decir del establecimiento de lo que el autor alemán dijo y escribió. Como el resto de la admirable edición de las obras completas de Max Weber iniciada en 1976 y todavía lejos de concluirse, este primer cometido de la crítica se ha cumplido de forma excelente y no deja nada que desear. Sin embargo, la crítica contempla otras dos operaciones aparte del establecimiento del texto, a las que llamamos interpretación y evaluación (cf. Langlois \& Seignobos, 1898). La segunda operación de la crítica (interpretar) consiste en describir y explicar todo lo que se requiera para dejar claro el significado e intención del autor, es decir lo que el autor quiso decir en el texto establecido. La tercera operación crítica (evaluar) consiste en describir y explicar todo lo que se requiera para que quede claro cuál es el valor de lo que el autor dijo y quiso decir, valor, claro está, siempre relativo a los criterios que se argumenten ser relevantes para tal juicio. Desgraciadamente en ninguno de estos dos puntos podemos decir que la edición de la cátedra de Weber cumple su cometido: ni interpreta ni evalúa los cursos de Weber como habría que hacerlo ${ }^{16}$. La razón es probablemente que el editor, Wolfgang Mommsen, fue sin duda un gran conocedor de la obra de Max Weber, pero tampoco sabía de teoría económica. Una cuestión que se me escapa, sin embargo, es cómo pudieron la honorable Academia Bávara de las Ciencias y la prestigiada editorial Mohr darse el lujo de ceder esta labor a alguien que no sabía de la disciplina, y que,

15. Crespo (1997:43) dice que el juicio de Mises acerca de Weber es «un poco duro" y que «todo depende del concepto de economía» que se tenga en mente. Por las razones que he venido dando me permito discrepar de esta opinión: la cosa es más honda y depende no del concepto de economía, sino del concepto mismo de teoría. Weber, como la mayoría de los sociólogos, llama "teoría» a todo tipo de cosas que no lo son. Soy naturalmente consciente de que muchos estudiantes y profesores usan la palabra «teoría» de muchas maneras (cf. Abend 2008), y no me interesa entrar en disputas verbales. Independientemente de las palabras, la cosa de la que hablan los economistas cuando hablan de teoría económica es algo completamente distintivo, y esa cosa no está presente en Weber.

16. La distinción entre las tres operaciones fundamentales de la crítica es lógica. Se entiende que no constituyen, ni cronológica ni psicológicamente, una secuencia lineal. Antes el contrario, el crítico va de una a la otra según los requerimientos de su investigación; y de hecho, cualquiera de las tres operaciones alimenta las otras dos y es alimentada por ellas continuamente. En ese sentido, aunque estoy impresionado por el ingente trabajo que significó editar las notas de Weber, creo que si Mommsen hubiese comprendido (interpretado) y apreciado (evaluado) mejor su contenido, también habría producido una mejor edición del texto. En particular, creo que su decisión de crear una especie de reproducción fidelísima de la forma en que esas notas se encuentran, simplemente yuxtaponiendo las variantes relacionadas, no es la más feliz. Hubiese sido mejor seguir la tradición de los filólogos que han editado los fragmentos de la tradición clásica antigua, atreviéndose a unir los disiecta membra y dar una mayor claridad al pensamiento de Weber. Una edición así, con todos los pasajes difíciles debidamente anotados, hubiera resultado de mayor provecho a los estudiosos de la historia de las ciencias sociales, amén de que su lectura sería más agradable y útil. 
además, ni siquiera invitaran a un economista como colaborador o asesor de esta edición. La única explicación que se me ocurre es la vieja rencilla familiar que continúa separando a los sociólogos de los economistas.

La cosa no tendría sino una importancia histórica, y además lejana para los lectores de esta revista, si no fuera por el hecho que se ha vuelto de rutina en nuestros estudiantes de sociología el emprender estudios de fenómenos sociales en los que las cuestiones económicas juegan un papel considerable, si no es que determinante, sin que se les sugiera, recomiende o más propiamente exija que aprendan al menos los fundamentos de la teoría económica. Por ser este el caso, y por no verse en el horizonte que las cosas vayan a cambiar pronto para mejor, creo que el caso de Max Weber como profesor de economía resulta instructivo y tal vez digno de meditación ${ }^{17}$.

\section{Referencias bibliográficas}

ABEND, Gabriel (2008) «The meaning of 'theory'». Sociological Theory 26(2), 173-199.

AlberT, Michel (1991) Capitalisme contre capitalisme. París: Seuil.

BÖHM-BAWERK, Eugen (1881). Rechte und Verhältnisse vom Standpunkte der volkswirthschaftliche Güterlehre: Kritische Studie. Innsbruck: Universitäts-Buchhandlung.

CRESPO, Ricardo F. (1997). «Max Weber and Ludwig von Mises, and the methodology of the social sciences». En: KosLOWSKI, Peter (ed.). Methodology of the social sciences, ethics, and economics in the Newer Historical School: from Max Weber and Rickert to Sombart and Rothacker (pp. 32-51). Heidelberg: Springer.

DASGUPTA, Parta y SERAGELDIN, Ismail, coords. (2000). Social capital: a multifaceted perspective. Washington (DC): The World Bank.

GINTIS, Herbert S. (2009). The bounds of reason: game theory and the unification of the behavioral sciences. Princeton (NJ): Princeton University Press.

HAYEK, Friedrich A. (1968). «Einleitung». En: MENGER, Carl. Gesammelte Werke, vol. 1 (pp. VII-XXXVI). Tubinga: Mohr.

HenNIS, Wilhelm (1987). Max Webers Fragestellung: Studien zur Biographie des Werkes. Tubinga: Mohr.

HOMANS, George Caspar (1964). «Contemporary theory in sociology». En: FARIS, R.E.L. (ed.). Handbook of modern sociology (pp. 951-77). Chicago: Rand McNally. [Reimpreso en Homans, G.C. Certainties and doubts: collected papers, 1962-1985 (pp. 17-53). New Brunswick (NJ): Transaction.]

17. Es posible constatar una y otra vez que los más celebrados sociólogos, tanto clásicos como contemporáneos, sufren de una profunda ignorancia respecto de la teoría y análisis económicos, al tiempo que se arrogan el derecho tanto de hablar de economía (sin saber) como de subestimar o minimizar el trabajo de los economistas. Max Weber es aquí el ejemplo (no menor), pero otro tanto podría hacerse con otros sociólogos clásicos (como Durkheim y Parsons) o contemporáneos (como Giddens, Habermas o Bourdieu) que adornan los currícula de nuestras licenciaturas y posgrados. El presente ejercicio, sin embargo, me parece ser especialmente iluminador por el hecho curioso de haber Weber efectivamente ejercido la docencia como profesor de economía, algo que no parece haberle ocurrido a ningún otro sociólogo famoso. Excluyo naturalmente el caso de Pareto, quien hace ya mucho tiempo padeció una defenestración que no ha sido ni revocada ni explicada. 
- (1983). «Steps to a theory of social behavior». Theory and Society, 12 (1), 1-45.

Huerta De Soto, Jesús (2009). Dinero, crédito bancario y ciclos económicos. $4^{\mathrm{a}}$ edición. Madrid: Unión Editorial.

INGRAM, John Kells (1888). History of political economy. Edinburgo: Adam \& Charles Black.

LANGLOIS, Charles-Victor y SEIGNOBOS, Charles (1898). Introduction aux études historiques. París: Hachette.

MEINER, Felix, coord. (1924). Volkswirtschaftslehre der Gegenwart in Selbstdarstellungen, vol. 1. Lepizig: Meiner.

MENGER, Carl (1871). Grundsätze der Volkswirthschaftslehre. Viena: Wilhelm Braumüller.

- (1883). Untersuchungen über die Methode der Socialwissenschaften, und der Politischen Oekonomie insbesondere. Leipzig: Duncker \& Humblot.

- (1884). Die Irrthümer des Historismus in der deutschen Nationalökonomie. Viena: Alfred Hölder.

Mises, Ludwig (1912). Theorie des Geldes und der Umlaufsmittel. Munich y Leipzig: Duncker \& Humblot.

- (1929). "Soziologie und Geschichte: Epilog zum Methodenstreit in der Nationalökonomie». Archiv für Sozialwissenschaften und Sozialpolitik, 61 (3), 465512. [Reimpreso en MISES, Ludwig (1933). Grundprobleme der Nationalökonomie: Untersuchungen über Verfahren, Aufgaben und Inhalt der Wirtschafts- und Gesellschaftslehre. Jena: Gustav Fischer.]

- (1957). Theory and history: an interpretation of social and economic evolution. New Haven (CT): Yale University Press.

Mommsen, Wolfgang, ed. (2009). Max Weber Gesamtasugabe, División III, Vorlesungen und Vorlesungsnachschriften, Tomo I, Allgemeine ("theoretische») Nationalökonomie: Vorlesungen 1894-1898. Tubinga: Mohr.

Norkus, Zenonas (2001). Max Weber und Rational Choice. Marburgo: Metropolis.

O’Boyle, Edward J. (2007). «Requiem for homo economicus». Journal of Markets and Morality, 10 (2), 321-337.

Pantaleoni, Maffeo (1889). Principii di economia pura. Florencia: Barbèra.

PARETO, Vilfredo (1896). Cours d'économie politique, vol. I. Lausana: Rouge.

PERSKY, Joseph (1994). «Retrospectives: the ethology of homo economicus». Journal of Economic Perspectives, 9 (2), 221-231.

PRIDDAT, Birger P. (1995). Die andere Ökonomie: eine neue Einschätzung von Gustav Schmollers Versuch einer "ethisch-historischen» Nationalökonomie im 19. Jahrhundert. Marburg: Metropolis.

ROSCHER, Wilhelm (1843). Grundriss zu Vorlesungen über Staatswirthschaft nach geschichtlicher Methode. Gotinga: Dieterich.

ROSENBERG, Alex (2009) «If economics is a science,, what kind of a science is it?» En: KINCAID, Harold \& Ross, Don (eds.) The Oxford handbook of philosophy of economics (pp. 55-67). Nueva York: Oxford University Press.

Rothbard, Murray N. (1983). The mystery of banking. Nueva York: Richardson \& Snyder.

SCHMOller, Gustav von (1883). "Zur Methodologie der Staats- und Socialwissenschaften». Jahrbuch für Gesetzgebung, Verwaltung und Volkswirthschaft im deutschen Reiche, Neue Folge, 7, 239-258. [Reimpreso en: SCHMOLLER, Gustav von (1888). Zur Litteraturgeschichte der Staats- und Sozialwissenschaften (pp. 275304): Leipzig: Duncker \& Humblot.]

SCHUMPETER, Joseph (1954). History of economic analysis. Nueva York: Oxford University Press. 
Swedberg, Richard (1998). Max Weber and the idea of economic sociology. Princeton (NJ): Princeton University Press.

- (1999). «Max Weber as an economist and as a sociologist: towards a fuller understanding of Weber's view of economics». American Journal of Economics and Sociology, 58 (4), 561-582.

WeBER, Marianne (1926). Max Weber: Ein Lebensbild. Tubinga: Mohr.

Weber, Max (1894). «Die Börse. I: Zweck und äussere Organisation». Göttinger Arbeiter-Bibliothek, vol. 1, pp. 17-48. [Reimpreso en: WEBER, Max (1922). Gesammelte Aufä̈tze zur Soziologie und Sozialpolitik (pp. 256-288). Tubinga: Mohr.]

- (1990) Grundriss zu Vorlesungen über allgemeine ("theoretische») Nationalökonomie. Tubinga: Mohr.

WiCKSTEED, Philip (1910). The common sense of political economy, including a study of the human basis of economic law. Londres: Macmillan. 